\title{
Roadmap to Project Management Office (PMO) and Automation using a Multi-Stage Fuzzy Rules System
}

\author{
Magdi Amer ${ }^{1}$ \\ Faculty of Computer \& Information Systems \\ Umm Al-Qura University \\ Mecca, KSA
}

\author{
Noha Elayoty $^{2}$ \\ Project Management Consultant \\ Canada
}

\begin{abstract}
The Project Management Office (PMO) has proven to be a successful approach to enhance the control on projects and improve their success rate. One of the main functions of the PMO is monitoring projects and ensuring that the adequate processes are applied if a project starts to slip. Due to the high complexity of the parameters involved in choosing the actions to take depending on the type and status of the projects, organizations face difficulties in applying the same standards and processes on all projects across the organizations. In this paper, the authors will provide an overview of the main functions of the PMO, suggest a roadmap to start a PMO function within an organization and the authors will propose an architecture to automate the monitoring and control function of a PMO using a multi-stage fuzzy rules system.
\end{abstract}

Keywords-Roadmap to build a PMO; automating the PMO; multi-stage Fuzzy System

\section{INTRODUCTION}

There is no general agreement on the definition of a PMO [1]. Historically, the PMO was created in industries such as aerospace and heavy construction, that have multiple critical projects running simultaneously [2]. The PMO roles were to ensure that knowledge is shared between projects, to standardize the use of methodologies, standards and best practices across all projects, to measure the PKIs of the project and to provide reports for upper management [2]. Due to the proven success of the PMO [3], more industries, companies and governmental entities decided to build their own PMO.

A PMO has three core roles: monitoring, support and enforcing standards. Many companies added more functions to the PMO, such as strategic planning, quality assurance, process improvement and even the project managers capability, which is usually called the Project Portfolio Management (PPM). Although this approach is sometimes justified due to financial or business constraints, it is not the main job of the PMO and special care needs to be provided so that the PMO does not lose focus on its core functionalities.

Moreover, the PMO's goal is to insure the success of the project, which in some cases may be in direct conflict with the goals of the other functions that have been added to the PMO. It is not a good idea to assign to the PMO conflicting roles as it will often place it in a position of conflict. This will limit the assertiveness of the PMO and thus limit its success. For example, the PMO often needs to report projects' data to higher managers that would result in putting the project under governess focus and thus putting pressure on the project manager of this project. If the PMO is assigned the role of the PPM, the PMO will find itself in a conflicting position of having to defend the project manager as the PPM, and also to increase this pressure as the PMO.

Building a PMO costs money, thus the decision on when to build it and what roles should be assigned to the PMO is business driven. A company may decide to focus on some PMO roles and delay the implementation of other roles depending on the business need of the company. It is understood that a partially implemented PMO will not provide the expected effect of a fully functional PMO, which explains the contradictions that were found in several studies on the impact of PMO [4] and [3].

In the next section, a summary of the state of the art will be provided, then the paper will explain in more details the functions of the PMO. Next the paper will propose a roadmap to building the PMO, then it will propose the automation of the monitoring function of the PMO using intelligent agents and fuzzy logic. The conclusion will be provided I the final section.

\section{LITERATURE REVIEW}

The Project Management Institute (PMI) defines the PMO as "a management structure that standardizes the projectrelated governance processes and facilitates the sharing of resources, methodologies, tools, and techniques." [5]. The PMI defines three types of PMO: Supportive PMO whose role is restricted to providing consultations, Controlling PMO whose role is to provide consultation and impose standards and Directive PMO whose role is to directly manage the projects. The problem with these definitions is that they do not try to explain the core functions of the PMO and they do not identify the optional functions that may be assigned to the PMO. The effect of the lack of definitions of the core functions of the PMO can be seen in several research papers, where authors evaluated incomplete or immature PMOs, and thus provided results that are not pertinent to the PMO.

The business survey conducted by KPMG in 2017 [6] points out the problems many organizations face to define the role of the PMO, to ensure the long-term success of the PMO and to maximize the advantages of having a PMO. In this survey, the main reasons that were behind the organizations' decision to build a PMO was to improve governance, to prioritize investment, align and adjust to business strategy and to enable consistency of delivery. Nevertheless, the ambiguous 
role of the PMO and its incomplete implementation often limits the effectiveness of the PMO. Moreover, there is usually a gap between what the organizations' executives expect from the PMO and what it actually does. KPMG recommends that the role of the PMO should become more visible and that the PMO should focus more on project support, guidance and alignment with the strategic plan of the organization.

In [7], the authors point to the problem of determining the value of the PMO despite the variation in the mandate and functions of a PMO from one organization to another. They suggest measuring the value of the PMO by determining the purpose for which it was created and evaluating if it was capable of fulfilling this purpose, by determining the values of the capabilities the PMO brings to the organization or by measuring the improvement in the KPIs related to the performance of the portfolio of projects.

In [4], the authors tested the effect of having a PMO on meeting the project schedule, on abiding to the budget and on following standardized project management. The authors found that there is no evidence that a PMO presence will affect the project schedule or the project management standardization, but it does improve the ability to complete a project within budget. In our opinion, the authors did not take into consideration the level of maturity of the PMOs of the companies included in the study. This is a direct result of the fact that the roles and responsibilities of a PMO are not well defined. One of the main goals of our research is to define what are the minimum functions that need to be present to consider that a PMO has reached a level of maturity and effectiveness to qualify as an active PMO.

In [3], the authors did not consider that project reviewing was part of the PMO. Instead, they considered that the PMO role was limited to process improvement and providing support for PMs. Furthermore, they measured the effect of project review and of the PMO separately. They found that both PMO and project reviews improve project performances; they both have a strong effect on projects with high uncertainty.

In [8], the authors investigated the effect of the Project Management Office role in the delivery of technology projects in mobile communication companies in Kenya. They found that the PMO has a high impact on the success of projects and they strongly recommend the adaptation of the PMO.

Using fuzzy logic to adequately calculate the status of a complex system has been an active area of research since Lotfi Zadeh invented fuzzy logic [9]. To deal with complex systems having multiple fuzzy input variables, many researchers has proposed building multi-stage systems, with each stage having a limited number of input variables, thus making it easier to design.

\section{THE PMO FUNCTIONS}

Before explaining the functions of the PMO, the roles and functions of the Project Managers' Practice need to be explained as there is often confusion between the roles and responsibilities of the PMO and the PM practice.

Often, the company will contain multiple practices for PMs, developers, testing and analysts. The PM practice focuses on the PM. The PM practice cares about the PM as a resource, provides support, trains the PMs, builds the career path for each PM, hires PMs, allocates PMs, increases their utilization and handles any problem related to the PM. The process improvement may be inside the PM practice, inside the PMO or a standalone entity with collaboration with the PPM and the PMO.

On the other hand, the PMO's focus is on the project as a business asset of the organization. Often, the PMO will use the project's PM as the single point of contact to collect the KPIs of the project.

The core functions of the PMO are monitoring, providing support and enforcing standards. The PMO may be assigned other roles such as project auditing, process improvement, collection of best practices and availing Subject Matter Experts (SMEs).

The monitoring projects function focuses on collecting projects' data regularly. The monitoring team processes this data to generate various reports to each manager based on the manager's level and responsibilities. The monitoring team continuously analyzes the data to assess the status of each project and to detect potential problems.

The support role of the PMO is provided when there is a need for it. This need may arise while the project is still in the green or when the PM is facing a business or technical problem that is placing a risk on the project. When the project starts to fall behind, a root cause analysis is conducted under the supervision of the PMO and a Go-To-Green plan will be developed as a result of this effort. The level of details required in the root cause analysis and the Go To Green plan depend on various factors such as the percentage of slippage, the potential loss, the importance of the sector and how such a slippage may affect the reputation of the organization, thus affecting its ability to obtain new projects.

This support offered by the PMO may be provided in the following forms:

- Assigning technical people that will join the project for a limited time or permanently

- Consulting technical architects that will review the solution and the plan of the project

- Consulting senior PMs that will challenge the Go-ToGreen plan.

- Consulting other PMs in the organization that have experience with the technologies and tools used by the project and in the business sector of the project.

- Providing the lesson learned from the lesson learned repository for project that have faced comparable problems.

- Consulting financial and sales teams that help obtain CRs from the customer

- Asking for support from the legal team for contract negotiation and for persuading the customer to respect the conditions and scope of the contract 
The PMO is also responsible for enforcing standards. In fact, the organization may decide to adopt a new process, technology or tool due to a business need to acquire experience in a strategic area, to increase the quality of the product or to increase the customer satisfaction. In this case, the PMO is responsible for imposing the process of adoption of the change and for handling the resistance that may face the adoption of this change. This resistance may be justified from the point of view of the PM and the project team members as this change may induce delays and place stress on projects that are already facing difficulties.

The PMO will be responsible for determining the criteria based on which of the projects adopting this change first will be chosen. This choice will be a function of parameters such as the phase of the project, the financial parameters of the project, the project sector or technologies used. The PMO should not try to impose any change on the PM as the PM should be in full control of the project. Instead, the PMO should increase the priority of the implementation of this change and leave the decision on when to adopt it to the PM. An alternative approach is to request from the PM to provide an estimate in the cost and time if this change is adopted immediately or if it is adopted at the start of the next phase or iteration. These estimates may be challenged by the PMO team and the decision of when to adopt this change should be made in light of these revised estimates.

The PMO is often made responsible for other functions. Most notably, it is often a good practice to assign the PMO with the responsibility to collect the lesson learned. Otherwise, the lesson learned collection responsibility will be distributed between multiple practices and geographical locations, making the access to these lessons learned hard, if possible at all. Auditing the project may also be assigned to the PMO, as they are already responsible for collecting the KPIs of the project.

\section{ROADMAP TO BUILDING THE PMO}

To build the PMO, the following steps are recommended:

1) Conduct analysis sessions to determine the KPI for all the projects and the level of detail that will be made available to each level of management. KPIs may be different from one sector to another, depending on the importance of the sector and the strategic areas on which the company is focusing.

2) Determine the different views and level of details that are made available to the managers, as a function of the manager level, role and sector.

3) Determine the report content, look and graphs used.

4) For each KPI, determine the actions to be taken in case of slippage of the PKIs of a project.

There are multiple parameters that may affect the choice of the action to be taken in case of project slippage. These parameters include:

- KPI value, reflecting the amount of slippage in time, expense and amount of scope creep

- The importance of the sector of the project

- The importance of the customer
- Financial parameters:

o Total cost of the project

o Expected gain from the project

o Potential loss due to penalties

- Project stage

- The history with the customer from the point of view of collaboration, acceptance of Change Requests and respect of the agreed upon features.

- Risk on reputation, as the preservation of the company reputation may make losses acceptable.

5) Determine when the information will be provided by the PMs. This may vary depending on the sector, project total value, project financial state (ahead of schedule, below cost, at cost, small financial slippage, large financial slippage) and the project schedule state (on schedule, small time slippage, large time slippage).

6) Determine how the PMO will communicate with other functions and practices and impose rules on when the PMO input is recommended or required.

7) Determine the phases during which the PMO will affect the project

8) Determine the tools that will be used to produce these reports. These tools may be simple excel files, commercially available products or custom made software.

The best approach is to implement the PMO in phases. The first phase will run using simple document templates. Then, the PMO initiative success will be evaluated and processes, reports and actions will be revisited. After the PMO team becomes confident of the maturity level of the PMO, the decision to buy a commercial application or to use a custom made software will be made. There is a trade-off between the two approaches. Using commercial applications or tools will usually be cheaper and the availability of these tools and applications will be faster, but the process of adapting these tools and applications to the needs of the company, the training required to use the tools and the preparation of the data in a format that the tools can understand at each reporting cycle may be a real burden. On the other hand, using custom software is usually easier, the software will retrieve the data from the available sources and there is a better control on the look of the produced report and the data that is available for different managers. Nevertheless, custom software is usually more costly and will take longer to become available. The decision on the approach to take is a business decision and the PMO team should explain clearly the benefit and pitfalls of each approach to the managers to help them choose the solution that better satisfies the needs of the company.

9) Determine how the PMO should be adopted. The PMO implementation could use a big-bang approach, in which case all the projects will start using the PMO on a specific date. This approach will enforce the culture of using the PMO and will send a clear message across the organization that the PMO adoption is not a choice but a requirement. On the other hand, 
the big-bang approach poses a risk as the limited knowledge of the modified processes could cause delays that will affect many projects. Moreover, there will be a limited number of experts familiar with the tools and processes, making helping all the projects at once and training all the PMs a challenging task.

Most organizations that have implemented the PMO have chosen to use a gradual approach, where the team of PMO experts will focus on a limited number of projects. After the successful adoption of the PMO and after the members of these projects have gained enough hands on experience on how to adopt the PMO, the PMO team will use another set of projects and will use the members of the teams that have already implemented the PMO as junior experts to help speed up the rolling out of the PMO.

In this case, it is recommended that the PMO imposes the criteria that will be used to select which of the projects should adopt the PMO first. In fact, if the choice is left to the practice, they may choose projects that are too easy or too complicated with a lot of issues, in which case the evaluation of the PMO results may not reflect the true value of the PMO. The criteria on which the projects are chosen may depend on the remaining time, the total cost, the current phase the project is in or the time or percentage of effort remaining to finish the phase the project is in.

The authors recommend that the PMO adoption should be used mainly at the beginning of new phases in the projects, as the implementation in the middle or toward the end of a phase may introduce confusion. Furthermore, it may require time to learn the new tools and understand how to adopt the new processes, which may introduce delays or may affect the quality of the final product.

\section{Automating the Functions OF PMO USING INTELLIGENT AGENT}

Monitoring a project is a complex task due to the various parameters of the project that needs to be considered. Based on these parameters, the state of each project will be evaluated to choose the most appropriate action plan to be taken if needed. These parameters may vary from one company to another based on the type of company, the company's expertise and the company's business processes.

TABLE I. THE LIST OF PARAMETERS AND THEIR TYPES

\begin{tabular}{|l|l|}
\hline Parameter Name & Parameter Type \\
\hline Customer importance & Manual \\
\hline Contract Value & Formula \\
\hline Time Slippage & Formula \\
\hline Cost Slippage & Formula \\
\hline Solution Technical Difficulty & Manual \\
\hline Customer Cooperation History & Manual \\
\hline Scope Creep & Manual \\
\hline Penalty Risk & Manual \\
\hline Reputation Risk & Manual \\
\hline
\end{tabular}

Some of these parameters represent abstract concepts and cannot be measured. These parameters are entered manually by the stakeholders who decide the value for these parameters. Parameters that are entered manually use a slide bar starting from $0 \%$ to $100 \%$ with $10 \%$ increments. Examples of such parameters is the complexity of the technical solution and the level of collaboration of the client. Other parameters will be directly calculated using a formula from the data of the project, such as the parameter reflecting the time slippage and that reflecting the cost slippage of the project.

Table 1 presents the parameters that were chosen in our system to monitor the projects and whether they are manually entered or evaluated using a formula.

Next, the crisp values of these parameters are fuzzified using custom membership functions to transfer these parameters into fuzzy parameters with 3 labels: Low, Medium and High.

To simplify the design of the system, it is implemented into multistage fuzzy system [10]. The rules used to give values to the intermediate fuzzy variables are subjective and the solution provided in this paper is only given as a guideline. The overview of the system is given in Figure 1.

In the first stage, using the parameters penalty risk and cost slippage, the potential cost slippage is calculated through fuzzy rules. Table 2 is used to summarize the fuzzy rules used to calculate the potential cost slippage.

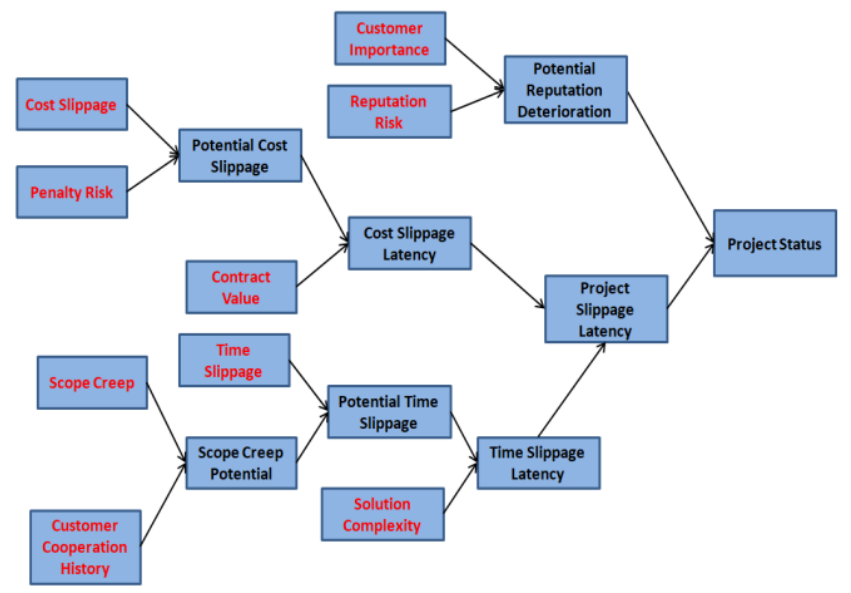

Fig. 1. Overview of the System Stages.

TABLE II. The CALCUlation of the Potential Cost SlipPage

\begin{tabular}{|l|l|l|l|l|}
\hline \multirow{2}{*}{ Potential Cost Slippage } & Cost Slippage \\
\cline { 3 - 5 } & Low & Medium & High \\
\hline \multirow{2}{*}{$\begin{array}{l}\text { Penalty } \\
\text { Risk }\end{array}$} & Low & Low & Medium & High \\
\cline { 2 - 5 } & Medium & Medium & High & High \\
\cline { 2 - 5 } & High & High & High & High \\
\hline
\end{tabular}

TABLE III. The Calculation of the Potential Cost SlipPage

\begin{tabular}{|l|l|l|l|l|}
\hline \multirow{2}{*}{ Cost Slippage Latency } & \multicolumn{3}{|l|}{ Potential Cost Slippage } \\
\cline { 3 - 5 } & Low & Medium & High \\
\hline \multirow{2}{*}{$\begin{array}{l}\text { Contract } \\
\text { Value }\end{array}$} & Low & Low & Low & Medium \\
\cline { 2 - 5 } & Medium & Low & Medium & High \\
\cline { 2 - 5 } & High & Medium & High & High \\
\hline
\end{tabular}


In the second stage, using the parameters contract value and potential cost slippage, the cost slippage latency is calculated through fuzzy rules. Table 3 is used to summarize the fuzzy rules used to calculate the cost slippage latency.

In the third stage, the parameters customer cooperation history and scope creep are used to calculate the Scope Creep Potential as shown in table 4.

TABle IV. The Calculation of the Potential Cost SlipPage

\begin{tabular}{|l|l|l|l|l|}
\hline \multirow{2}{*}{ Scope Creep Potential } & \multicolumn{3}{|l|}{ Customer Cooperation History } \\
\cline { 3 - 5 } & & Low & Medium & High \\
\hline \multirow{3}{*}{$\begin{array}{l}\text { Scope } \\
\text { Creep }\end{array}$} & Medium & Medium & Low & Low \\
\cline { 2 - 5 } & High & High & Medium & Low \\
\cline { 2 - 5 } & High & High & High & Medium \\
\hline
\end{tabular}

In the fourth stage, the parameters time slippage and scope creep potential are used to calculate the potential time slippage as shown in table 5

TABle V. The Calculation of the Potential Time SlipPage

\begin{tabular}{|l|l|l|l|l|}
\hline \multirow{2}{*}{ Potential Time Slippage } & \multicolumn{2}{|l|}{ Cost Slippage } \\
\cline { 3 - 5 } & & Low & Medium & High \\
\hline \multirow{3}{*}{$\begin{array}{l}\text { Scope Creep } \\
\text { Potential }\end{array}$} & Low & Low & Medium & High \\
\cline { 2 - 5 } & Medium & Medium & High & High \\
\cline { 2 - 5 } & High & High & High & High \\
\hline
\end{tabular}

In the fifth stage, the parameters potential time slippage and solution complexity are used to calculate the time slippage latency as shown in table 6.

TABLE VI. The CAlculation Of the Time SliPpage Latency

\begin{tabular}{|l|l|l|l|l|}
\hline \multirow{2}{*}{ Time Slippage Latency } & \multicolumn{3}{|l|}{ Potential Time Slippage } \\
\cline { 3 - 5 } & & Low & Medium & High \\
\hline \multirow{3}{*}{$\begin{array}{l}\text { Solution } \\
\text { Complexity }\end{array}$} & Low & Low & Low & Medium \\
\cline { 2 - 5 } & Medium & Low & Medium & High \\
\cline { 2 - 5 } & High & Medium & High & High \\
\hline
\end{tabular}

In the sixth stage, the parameters cost slippage latency and time slippage latency are used to calculate the Project Slippage Latency as shown in table 7.

TABLE VII. The Calculation of the ProjeCt SlipPage Latency

\begin{tabular}{|l|l|l|l|l|}
\hline \multirow{2}{*}{ Project Slippage Latency } & \multicolumn{3}{l|}{ Time Slippage Latency } \\
\cline { 3 - 5 } & Low & Medium & High \\
\hline $\begin{array}{l}\text { Cost } \\
\text { Slippage } \\
\text { Latency }\end{array}$ & Medium & Low & Medium & High \\
\cline { 2 - 5 } & High & High & Very High & Critical \\
\cline { 2 - 5 }
\end{tabular}

In the seventh stage, the parameters reputation risk and customer importance are used to calculate the potential reputation deterioration as shown in table 8 .

TABLE VIII. The POTENTIAL REPUTATION DETERIORATION

\begin{tabular}{|l|l|l|l|l|}
\hline \multicolumn{2}{|l|}{$\begin{array}{l}\text { Potential Reputation } \\
\text { Deterioration }\end{array}$} & \multicolumn{4}{|l|}{ Customer Importance } \\
\cline { 3 - 5 } & Low & Medium & High \\
\hline \multirow{3}{*}{ Reputation Risk } & Low & Low & Low & Medium \\
\cline { 2 - 5 } & Medium & Low & Medium & High \\
\cline { 2 - 5 } & High & Medium & High & High \\
\hline
\end{tabular}

Table IX. The Calculation of the Potential Status

\begin{tabular}{|l|l|l|l|l|}
\hline \multirow{2}{*}{ Project Status } & \multicolumn{3}{l|}{ Potential Reputation Deterioration } \\
\cline { 3 - 5 } & Low & Medium & High \\
\hline \multirow{3}{*}{$\begin{array}{l}\text { Project } \\
\text { Slippage }\end{array}$} & Low & Low & Medium & High \\
\cline { 2 - 5 } & Medium & Medium & High & Very High \\
\cline { 2 - 5 } & High & High & Very High & Critical \\
\cline { 2 - 5 } & Very High & Very High & Critical & Critical \\
\cline { 2 - 5 } & Critical & Critical & Critical & Critical \\
\hline
\end{tabular}

In the eighth and final stage, the parameters project slippage latency and potential reputation deterioration are used to calculate the project status as shown in table 9 .

The system uses a set of fuzzy rules to choose the best actions to take depending on the values of the intermediate and final fuzzy variables. These rules would be used to determine the rate of the review meeting, the Go-To-Green steering committee members, the level of the managers that will be briefed about the project, the corrective actions that may be taken, such as adding members to the project team; using the consultation of senior PMs, risk managers, SMEs, technical architects, the sales team and the legal team; performing a root cause analysis; retrieving information about similar problems from the lessons learned database; deploying a crisis team on the customer's site and eventually the decision to terminate the project. All projects that facing potential problems will start appearing in the reports with the level of details varying depending on the manager's level and business interest. The decision on the amount of information that will appear in reports and the levels of the manager that will see these reports is part of the analysis made during the construction of the PMO.

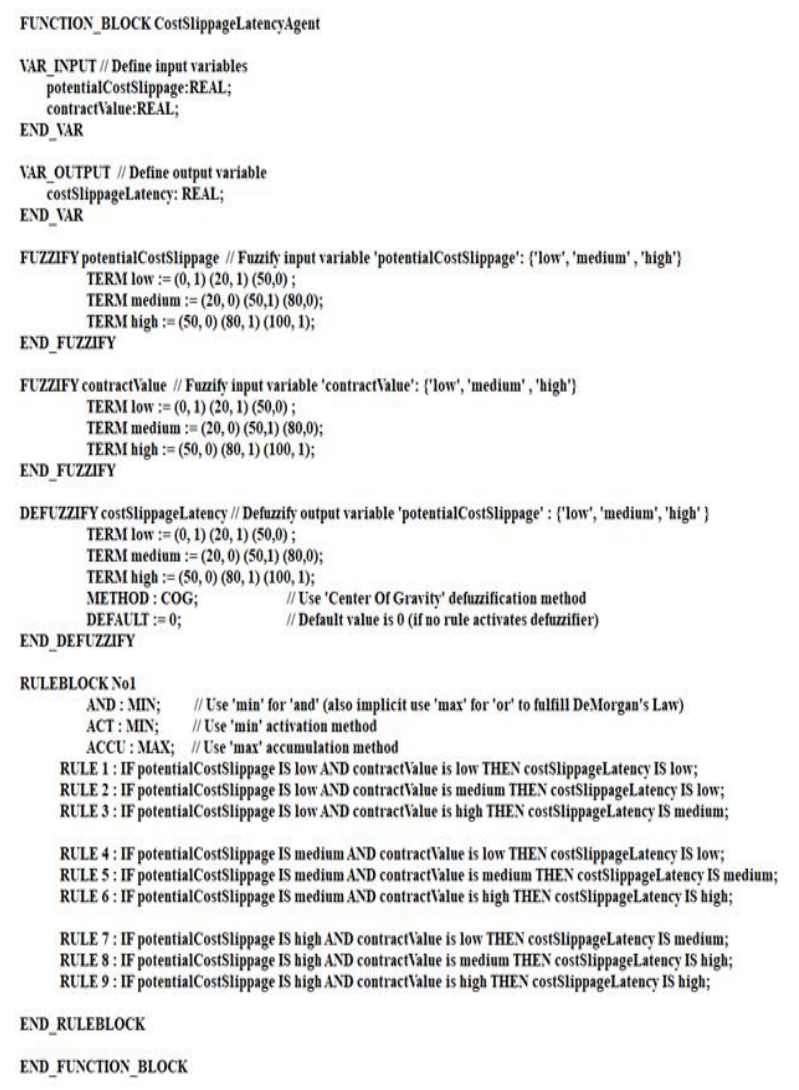

Fig. 2. Definition of the Cost Slippage Latency Agent. 
An alpha cut-off of $20 \%$ is used to prevent rules with a low level of truth value to be triggered and thus preventing the initiation of unnecessary actions.

The system was implemented based on the fuzzy logic library JFuzzyLogic [11] with some modifications made to improve the library's support for multi-stage computation of fuzzy rules. An agent was used to compute the value of each intermediate or final fuzzy variables. Figure 2 shows the definition of the Cost Slippage Latency Agent.

In our implementation, agents used fuzzy rules to determine the suitable value of each intermediate fuzzy variable. Nevertheless, other techniques may be used instead if needed.

The calculation of the project status is conducted in multiple stages. In the first stage, intermediate agents, which have all their input parameters obtained from the customer or from formulas, are calculated. The system then iterates several times, evaluating the output of all agents whose input parameters are ready. This is repeated till the final stage is calculated and the value of the project status is calculated.

\section{CONCLUSION}

The PMO has proven to play an important function in the success of organizations. This paper proposes a roadmap to build the PMO that is business driven and it also points to pitfalls that may reduce the success of the PMO. With multinational companies conducting projects in several countries, it is hard to enforce manual processes that are applied equally across the organization. Automating the PMO's function of monitoring projects and choosing the most suitable actions to mitigate project slippage seems the correct approach, thus providing an efficient method to intervene at early stages of project slippage to improve the chances of resolving the project issues.

Due to the complexity of the parameters involved in controlling projects, automating the PMO's monitor and control function is a challenging task. In this paper, a multiagents architecture using fuzzy logic has been proposed that reduces the complexity of the system by using a multi-stage approach to calculate the project status and to choose the proper set of actions that should taken. The system described in this paper is provided only as a guideline and companies should adapt the proposed model to represent the company goals and processes.

\section{REFERENCES}

[1] Hobbs, B., 2007, "The Multi-project PMO:: A Global Analysis of the Current State of Practice", white paper, PMI, 44 pages.

[2] Desmond, C., 2015, "Project Management Office", in IEEE Engineering Management Review, Volume 43, number 1, IEEE, pages 15-16

[3] Liu, L. , Yetton, P. , 2007 , "The Contingent Effects on Project Performance of Conducting Project Reviews and Deploying Project Management Offices", in IEEE transactions on Engineering Management, Volume 54, number 4, IEEE, pages 789-799.

[4] Martin, N.L. , Pearson, J.M., Furumo, K.A. , 2005, "IS Project Management: Size, Complexity, Practices and the Project Management Office", in Proceedings of the 38th Annual Hawaii International Conference on System Sciences, IEEE.

[5] Project Management Institute, 2017, "A Guide to the Project Management Body of Knowledge ( PMBOK® Guide )—Sixth Edition", Project Management Institute, 756 pages.

[6] KPMG, 2017, "Driving Business Performance: Project Management Survey", 2017, on-line: https://assets.kpmg.com/content/dam/kpmg/nz/pdf/July/projectmanagem entsurvey-kpmg-nz.pdf

[7] Van der Linde, J., Steyn, H., 2016, "The effect of a Project Management Office on project and organisational performance: A case study", South African Journal of Industrial Engineering, vol.27, n.1, http://dx.doi.org/10.7166/27-1-1114

[8] Munyoki. K. K., \& Njeru, A. W., 2014, "The Effect of Project Management Office Role in the Delivery of Technology Projects in Mobile Communication Companies in Kenya", in International Journal of Humanities and Social Science, Vol. 4 No. 3; pages: 211- 215

[9] Zadeh, L., 1996, "Fuzzy sets." Fuzzy Sets, Fuzzy Logic, And Fuzzy Systems, pages 394-432

[10] Yeh, Z.M., Li, K.H., 2004, A systematic approach for designing multistage fuzzy control systems, In Fuzzy Sets and Systems, 2004, Elsevier, Volume 143, Issue 2, Pages 251-273, https://doi.org/10.1016/S0165-0114(03)00203-3

[11] Cingolani, P., \& Alcala-Fdez, J., (2012). JFuzzyLogic: a robust and flexible Fuzzy-Logic inference system language implementation. In Fuzzy Systems (FUZZ-IEEE), 2012 IEEE International Conference on (pp. 1-8). IEEE, https://doi.org/10.1109/FUZZ-IEEE.2012.6251215 